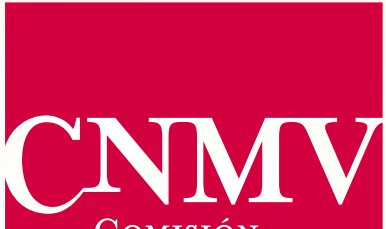

Comisión

NAGIONAL

DEL MERCADO

DE VALORES
Managerial ability, risk preferences and the incentives for active management

Ramiro Losada

Documentos de Trabajo $N^{\circ} 62$ 



\section{Managerial ability, risk preferences and the incentives for active management $(*)$}

Ramiro Losada $(* *)$

Documentos de Trabajo

$\mathrm{N}^{\circ} 62$

March 2016

$\left(^{*}\right)$ I gratefully acknowledge the data provided by my colleagues from the Statistics department at the CNMV and the comments and help from Vicente Garcia, Toni Vaello, Pedro Serrano and Carlos Urbaneja. The usual disclaimer applies.

$\left.{ }^{(* *}\right)$ Comision Nacional del Mercado de Valores. c/Edison 4, Madrid, 28006, Spain. TIf: +34915850912. Email: rlosada@cnmv.es 
Ramiro Losada is a member of the Research, Statistics and Publications Department, CNMV.

The opinions in this Working Paper are the sole responsibility of the authors and they do not necessarily coincide with those of the CNMV.

The CNMV publishes this Working Paper Series to enhance research and contribute towards greater knowledge of the stock markets and their regulation.

The CNMV distributes its reports and publications via the internet at www.cnmv.es

(C) CNMV. The contents of this publication may be reproduced, subject to attribution.

Ramiro Losada pertenece al Departamento de Estudios, Estadísticas y Publicaciones de la CNMV.

Las opiniones expresadas en este documento relejan exclusivamente el criterio de los autores y no deben ser atribuidas a la Comisión Nacional del Mercado de Valores.

La Comisión Nacional del Mercado de Valores, al publicar esta serie, pretende facilitar la difusión de estudios que contribuyan al mejor conocimiento de los mercados de valores y su regulación.

La Comisión Nacional del Mercado de Valores difunde la mayoría de sus publicaciones a través de la red Internet en la dirección www.cnmv.es

(C) CNMV. Se autoriza la reproducción de los contenidos de esta publicación siempre que se mencione su procedencia.

ISSN (edición electrónica): 2172-7147

Maqueta: Composiciones Rali, S.A. 


\section{Abstract}

This paper uses a structural econometric model to assess the managerial ability of Spanish management companies. Traditionally, ability has been mainly measured by the alphas of CAPM models. The model used in this paper allows to disentangle the ability and preferences that are embedded in alphas. The results show that the abilities of Spanish management companies are lower than their peers in the US. This result could be the consequence of the limited competition in the mutual fund market as well as the narrowness of the equity markets that the funds invest in. Moreover, it is shown that the fraction of the funds' portfolios that is actively managed does not depend on the fees paid and it is negatively correlated to funds' total assets and whether a fund belongs to a credit institution's management company.

Keywords: Ability, incentives, active management.

JEL Classification: G1 1, G23, C58. 



\section{General index}

$2.1 \quad$ Structural mode

2.2 Model solution

2.3 Econometric Framework

3 Data

$4 \quad$ Results

$\begin{array}{llr}4.1 & \text { Estimates of the structural parameters } & 29\end{array}$

\begin{tabular}{lll}
\hline 4.2 & Structural model's alphas and betas & 32 \\
\hline
\end{tabular}

\begin{tabular}{lll}
\hline 4.3 & On active management & 32
\end{tabular}

\begin{tabular}{ll}
4.3 & 32 \\
\hline
\end{tabular}

$\begin{array}{lll}4.4 & \text { Correlation between active fund returns } & 35\end{array}$ 



\section{Index of Figures}

\section{Index of Tables}

\begin{tabular}{llr} 
TABLE 1 & Descriptive statistics of the data set & 27 \\
\hline TABLE 2 & Structural parameters estimates & 29 \\
\hline TABLE 3 & Structural parameters estimates: Non-independent management companies & 31 \\
\hline TABLE 4 & Structural parameters estimates: Independent management companies & 31 \\
\hline TABLE 5 & Estimates of $a$ and $\beta$ from the structural model and performance regressions & 32 \\
\hline TABLE 6 & Estimation results: size of the active portfolio us fund's fees & 33 \\
\hline TABLE 7 & Estimation results: size of the active portfolio us fund's total asset & 34 \\
\hline TABLE 8 & Estimation results: size of the active portfolio us ability & 34 \\
\hline TABLE 9 & Estimation results: size of the active portfolio us type of management company & 35 \\
\hline
\end{tabular}





\section{Introduction}

The literature on mutual fund has extensively studied two issues: first, whether it is better to choose an equity fund that is actively managed or to follow a benchmark, and, secondly, how managers' incentives influence the investment risks they assume. ${ }^{1}$ Since Jensen (1968), these issues have been tackled through the use of performance regressions. ${ }^{2}$ This type of modelling allowed to assess ability and risk taking without explicitly modeling the manager's investment decision problem.

In this paper, a version of the Koijen (2014) dynamic investment model for mutual fund managers has been used. This model does permit the study of the cross-sectional distribution of the managers' ability, incentives and risk preferences. The model proposes a manager's problem for which the solution is a dynamic investment strategy that is translated into the funds returns observed in the data. This empirical strategy has the benefit of separating out the managers' ability, risk preferences and incentives.

In order to estimate the model, an econometric framework that enables the estimation of a large class of continuous-time optimization problems by maximum likelihood was used. This estimation method uses the martingale method described by Cox and Huang (1989). Koijen (2014) showed how this method can be used to estimate continuous-time optimization models, in addition to solving them. He proposed to construct the likelihood of the continuous-time model, even if the optimal investment strategy was not known in closed form.

There is a controversy surrounding the existence of managerial ability that arises largely from inefficient inference. ${ }^{3}$ It is well known that averaging returns over short time spans leads to noisy estimates (Merton (1980)). Hence, the estimated cross-sectional distribution of managerial ability reflects not only true heterogeneity, but also, and perhaps predominantly, an estimation error. The restrictions implied by models of delegated portfolio management, as Koijen (2014), lead to much sharper estimates of managerial ability and risk aversion because they can exploit information in the volatility of fund returns and in the covariance of fund returns and benchmark returns. Given the estimates of managerial ability and risk aversion, the cross-sectional distribution of the standard performance measure, alpha, can be recovered.

1 See Wermers (2011).

2 The typical approach to measuring ability has been to regress mutual fund returns in excess of the short rate on a set of passive benchmarks, and to take the intercept of this regression, the fund's alpha, as measure of ability.

3 Pastor and Stambaugh (2002), Lynch and Wachter (2007a) and Lynch and Wachter (2007b) propose using longer samples of benchmark returns to sharpen the estimates. Managerial ability is still estimated by averaging risk-adjusted returns over short periods. 
The aim of the paper is to estimate the structural model proposed by Koijen (2014) for the Spanish equity mutual funds during the period 1995-2014. The parameters of each fund have been estimated using data collected by the Spanish Securities and Exchange Commission (CNMV) and Datastream. The key structural parameters of interest were the manager's ability, the risk aversion coefficient, and the pay for performance sensitivity of the compensation contracts. As stated in Cambon and Losada (2014) and Losada (2015), within the Spanish market, in most of the segments of the mutual fund industry, the management companies that belong to credit institutions enjoy market power. It was also established that this type of management companies enjoy the least market power in the equity segment. Given this evidence, this paper studies separately the behaviour of the independent management companies and those that belong to credit institutions and tries to evaluate whether their ability, risk preferences and incentives are different.

One important feature of this model is that it disentangles each fund's portfolio risk into two complementary equity subportfolios, one that exclusively follows the benchmark and one that can be treated as actively managed. This allows the study of the size of managers' active portfolios. Lastly, the Swedish and Danish government and European Commission have voiced their concerns on whether mutual fund managers are engaged in true active management or mainly follow a benchmark. This paper tries to shed light on this issue and can assess to what extent Spanish equity mutual funds are actively managed.

This paper is related to a extensively literature on mutual fund performance. Most of this literature is based on comparing the performance of the funds with their benchmark. Most of the evidence found was negative, as the equity mutual funds rarely outperform their benchmarks. ${ }^{4}$ Similar results were found for the Spanish market. $^{5}$

The paper is structured as follows. Section 2 describes the structural model and the strategy used to estimate it. Section 3 presents the data used to study the Spanish equity mutual fund market. Section 4 presents and analyses the results of the empirical analysis. Finally, the last section lays out the conclusions.

4 See Sharpe (1966), Jensen (1968), Grinblatt and Titman (1989), and more recently, Malkiel (1995), Droms and Walker (1995), Ackermann et al. (1999), Deltzler (1999) and Edelen (1999).

5 See Ferrando and Lassala (1998), Basarrate and Rubio (1999), Matallin and Fernandez (1999), Menendez and Alvarez (2000), Martinez (2001), Fernandez et al. (2007) and Palacios (2010). 


\section{Model and the optimal investment strategy}

The model used in this paper follows Koijen (2014). The author proposed an structural dynamic investment model in which he studied the cross-sectional distribution of ability, incentives and risk preferences of equity mutual fund managers in the U.S. market. This model has three main ingredients: the financial market where managers operate, the managers' preferences and the managers' compensation contracts.

\subsection{Structural model}

\subsubsection{Financial Market}

It is considered that the each manager has access to three different types of portfolios of assets. The first asset is a cash account that is traded at a price of $S_{t}^{\circ}$. The cash account earns an interest rate $r$ and its dynamics satisfy:

$$
d S_{t}^{\circ}=S_{t}^{\circ} r d t, S_{\circ}^{\circ}=1,
$$

The second asset is the benchmark portfolio with price $S_{t}^{B}$ :

$$
d S_{t}^{B}=S_{t}^{B}\left(r+\bar{\sigma}_{B} \lambda_{B}\right) d t+S_{t}^{B} \bar{\sigma}_{B} d Z_{t}^{B}, S_{\circ}^{B}=1
$$

where $\lambda_{B}$ is the price of risk, $\bar{\sigma}_{B}$ is the standard deviation of the benchmark portfolio, and $Z_{t}^{B}$ is a standard Brownian motion. These coefficients are assumed to be constant during the investment period but the interest rates change every month.

Each manager $i$ can trade a manager-specific active portfolio with price $S_{i t}^{A}$. Without loss of generality, it is assumed that the active portfolio does not carry any systematic risk. This active portfolio overlays the benchmark portfolio. Its dynamic is as follows:

$$
d S_{i t}^{A}=S_{i t}^{A}\left(r+\bar{\sigma}_{A i} \lambda_{A i}\right) d t+S_{i t}^{A} \bar{\sigma}_{A i} d Z_{i t}^{A}, S_{i \mathrm{o}}^{A}=1 .
$$

The price of risk of the active portfolio, $\lambda_{A i}$, is taken as a measure of managerial ability (see also Nielsen and Vassalou (2004)). The parameter $\bar{\sigma}_{A i}$ denotes the volatility of the active portfolio. The risk price picks up the extent to which the active strategy improves the manager's investment feasible set in addition to the cash account and the benchmark portfolio. This risk price compensates the manager for the exposure to the active portfolio risk, $Z_{i t}^{A}$.

Three features of the trading technology are worth commenting on. Firstly, The model and the estimation strategy do not make any assumptions about the correla- 
tion between active strategies across managers. For any two managers $i$ and $j$, an arbitrary correlation between $Z_{i t}^{A}$ and $Z_{j t}^{A}$ is allowed. This is important as managers may implement correlated active strategies as it is pointed out in Cohen et al. (2005).

Secondly, the active portfolio does not have any exposure to the benchmark. This is not restrictive as the manager can also trade the benchmark itself. Thus, any benchmark exposure of the active portfolio can be offset by adjusting the position in the benchmark. It is better in that case, without loss of generality, to normalize the exposure of the active portfolio to zero. ${ }^{6}$

Lastly, short-sales or borrowing constraints are not imposed even though fund managers may face certain investment restrictions as it is described in Almazan et al. (2004). ${ }^{7}$ If the optimal beta exceeds one in the model, in financial terms, it means that the manager borrows cash and invests the proceeds in the benchmark, which by definition has a beta equal one. In practice, the manager can simply invest in stocks with betas that exceed one. The variation in mutual fund betas seems well within the range of betas offered by individual stocks or stock portfolios. If the manager faces constraints in terms of the positions in the active portfolio, this will be reflected by a lower estimate of $\lambda_{A i}$.

\subsubsection{Dynamics of assets under management}

In order to derive the dynamics of the mutual fund portfolio, $A_{t}$, a more compact matrix notation that simplifies the exposition is introduced:

$$
\Lambda \equiv\left(\begin{array}{c}
\lambda_{B} \\
\lambda_{A}
\end{array}\right), \sigma_{B} \equiv\left(\begin{array}{c}
\bar{\sigma}_{B} \\
\circ
\end{array}\right), \sigma_{A} \equiv\left(\begin{array}{c}
0 \\
\bar{\sigma}_{A}
\end{array}\right), Z_{t} \equiv\left(\begin{array}{c}
Z_{t}^{B} \\
Z_{t}^{A}
\end{array}\right) \text {, and } \Sigma \equiv\left(\begin{array}{c}
\sigma_{B}^{\prime} \\
\sigma_{A}^{\prime}
\end{array}\right) \text {. }
$$

All subscripts $i$ were suppressed to simplify notation. So, the dynamics of the assests under management are:

$$
\frac{d A_{t}}{A_{t}}=\left(r+\theta_{t}^{\prime} \Sigma \Lambda\right) d t+\theta_{t}^{\prime} \Sigma d Z_{t}, A_{\circ}=1,
$$

where $\theta_{t}^{\prime} \in \mathbb{R}^{2 \times 1}$ are mutual funds portfolio weights invested in the benchmark and the active portfolio. The remainder, $1-\theta_{t}^{\prime} \iota$ is invested in cash.

As it is assumed that financial market is dynamically complete, the stateprice density, $\varphi_{t}$, sums up the manager's investment feasible set. The dynamics of the stateprice density are given by:

$$
d \varphi_{t}=-\varphi_{t} r d t-\varphi_{t} \Lambda^{\prime} d Z_{t}, \varphi_{\mathrm{o}}=1
$$

In addition to fund returns as in (4), assets under management are affected by fund flows. The reaction of investors to the relative performance of a fund may have impor-

6 It is perhaps best to think of the active portfolio as a stock-selection strategy. It is easy to account for a market-timing portfolio as well, which would have a correlation with the benchmark.

7 In Spain, Royal Decree 1082/2012 which expands on the Law 35/2003 of the $4^{\text {th }}$ of October on collective investment schemes sets the restrictions the managers face when they select the portfolio of a mutual fund. 
tant implications for managers risk taking incentives. In this model, fund flows relative to initial assets, $f\left(R_{T}^{A}, R_{T}^{B}\right)$ are considered as being affine in relative performance:

$$
f\left(R_{T}^{A}, R_{T}^{B}\right) \equiv \frac{F\left(A_{\circ}, R_{T}^{A}, R_{T}^{B}\right)}{A_{\circ}}=\psi_{\circ}+\psi_{1} \frac{R_{T}^{A}}{R_{T}^{B}},
$$

where $F\left(A_{\circ}, R_{T}^{A}, R_{T}^{B}\right)$ is the flow in euros, $R_{T}^{B} \equiv S_{T}^{B} / S_{\circ}^{T}$, and $R_{T}^{A} \equiv A_{T} / A_{\circ}$. This means that the total mutual fund assests at the end of the investment period are:

$$
A_{T}+F\left(A_{\circ}, R_{T}^{A}, R_{T}^{B}\right)=A_{\circ} R_{T}^{A}+A_{\circ} f\left(R_{T}^{A}, R_{T}^{B}\right) .
$$

\subsubsection{The mutual fund manager's problem}

It is assumed that the manager of the mutual fund $i$ derives utility from end-of-period compensation, $Y_{i T}$. It is also assumed that the manager enjoys constant relative risk aversion (CRRA) preferences over compensation: ${ }^{8}$

$$
\max _{\left(\theta_{i t}\right)_{t \in[0, T]}} E_{\circ}\left[u\left(Y_{i T}\right)\right]=\max _{\left(\theta_{i t}\right)_{t \in[0, T]}} E_{\mathrm{o}}\left[\frac{1}{1-\gamma_{i}} Y_{i T}^{1-\gamma_{i}}\right]
$$

where $\gamma_{i}$ measures the manager's risk aversion. It is supposed that the manager maximizes his expected utility by dynamically choosing an optimal investment strategy, $\theta_{i t}$, between o and $T$, subject to the budget constraint (4).

There is little public information, on a per fund basis, about the compensation schemes of fund managers. As in Koijen (2014), managers' compensation consists of a base salary and a variable bonus, described by the following contract specification:

$$
Y_{i t}=\kappa_{i 0} A_{i 0}+\kappa_{i 1}\left(A_{i T}+A_{i 0} f\left(R_{T}^{A}, R_{T}^{B}\right)\right) .
$$

This contract has two components, the first one, $\kappa_{i 0} A_{i 0}$ is a constant base salary that does not depend on the manager's performance. It is assumed that the base salary is proportional to the assets under management at the beginning of the period. The variable component, $\kappa_{i 1}\left(A_{i T}+A_{i 0} f\left(R_{T}^{A}, R_{T}^{B}\right)\right)$ depends on the fund performance through the investment period. This variable component is taken to be proportional to the end of period fund value including flows (see (7)). ${ }^{9}$

As the fixed and variable parts are assumed to be proportional to initial fund assets, it can be derived that:

$$
Y_{i t}=A_{i 0}\left(\kappa_{i 0}+\kappa_{i 1}\left(R_{i T}^{A}+f\left(R_{T}^{A}, R_{T}^{B}\right)\right) .\right.
$$

This expression implies that the manager's objective function can be simplified to:

$$
\max _{\left(\theta_{i t}\right)_{t \in[o, T]}} E_{\circ}\left[\frac{1}{1-\gamma_{i}}\left(1+\kappa_{i}\left(R_{i T}^{A}+f\left(R_{T}^{A}, R_{T}^{B}\right)\right)^{1-\gamma_{i}}\right],\right.
$$


where $\kappa_{i} \equiv \kappa_{i 1} / \kappa_{i 0}$ is the measure of the sensitivity of the manager's payment for performance. When using the data, $\kappa_{i 0}$ and $\kappa_{i 1}$ cannot be identified separately, but only the ratio $\kappa_{1 i} / \kappa_{0 i}$ matters for the optimal investment strategy. So, it suffices to estimate $\kappa_{i}$ for each manager. Another important point is that, as the base salary and the variable component of the compensation contract scale with initial fund assets, the objective in (11) implies that the manager only cares about maximizing fund returns and funds returns relative to the benchmark, because relative returns affect fund flows by the measure $\psi_{1}$. So, the investment problem can be summarized by maximizing (11) subject to (4).

\subsection{Model solution}

In order to solve the model, the method of Cox and Huang (1989) is applied. From this subsection on, the subscripts are omitted again.

\subsubsection{Optimal level of assets under management}

As stated in the previous section the manager's optimization problem can be summarized as: ${ }^{10}$

$$
\begin{gathered}
\max _{R_{T}^{A} \geq 0} E_{\circ}\left(\frac{1}{1-\gamma}\left(1+\kappa \psi_{\circ}+\kappa\left(R_{T}^{A}+\psi_{1} \frac{R_{T}^{A}}{R_{T}^{B}}\right)\right)^{1-\gamma}\right) \\
\text { s.t. } E_{\circ}\left(\varphi_{T} R_{T}^{A}\right)=1
\end{gathered}
$$

by substituting equation (6) in equation (11). This means that the Lagrangian reads:

$$
\mathcal{L}=\frac{1}{1-\gamma}\left(1+\kappa \psi_{\mathrm{o}}+\kappa\left(R_{T}^{A}+\psi_{1} \frac{R_{T}^{A}}{R_{T}^{B}}\right)^{1-\gamma}\right)-\varepsilon\left(\varphi_{T} R_{T}^{A}-1\right) .
$$

If the first order condition is taken, the following is obtained:

$$
\left(1+\kappa \psi_{\circ}+R_{T}^{A} \kappa\left(1+\frac{\psi_{1}}{R_{T}^{B}}\right)\right)^{-\gamma} \kappa\left(1+\frac{\psi_{1}}{R_{T}^{B}}\right)=\varepsilon \varphi_{T} .
$$

Optimal time-T assets under management are given by

$$
R_{T}^{A}=\left(\frac{1}{\kappa\left(1+\frac{\psi_{1}}{R_{T}^{B}}\right)}\right)^{1-\frac{1}{\gamma}}\left(\varepsilon \varphi_{T}\right)^{-\frac{1}{\gamma}}-\frac{1+\kappa \psi_{\circ}}{\kappa\left(1+\frac{\psi_{1}}{R_{T}^{B}}\right)} .
$$

By no-arbitrage, optimal time-t assests under management follow:

$$
\begin{gathered}
R_{t}^{A^{*}}=E_{t}\left(R_{T}^{A} \frac{\varphi_{T}}{\varphi_{t}}\right)= \\
=E_{t}\left(\frac{\varphi_{T}}{\varphi_{t}}\left(\frac{1}{\kappa\left(1+\frac{\psi_{1}}{R_{T}^{B}}\right)}\right)^{1-\frac{1}{\gamma}}\left(\varepsilon \varphi_{T}\right)\right)^{-\frac{1}{\gamma}}-E_{t}\left(\frac{\varphi_{T}}{\varphi_{t}} \frac{1+\kappa \psi_{\circ}}{\kappa\left(1+\frac{\psi_{1}}{\mathrm{R}_{T}^{B}}\right)}\right)=
\end{gathered}
$$

10 A sufficient condition for a well defined problem is that $\psi_{1}>\psi_{0}$, which is satisfied in the estimated models. 


$$
\begin{gathered}
=\varepsilon^{-\frac{1}{\gamma}} \varphi_{t}^{-\frac{1}{\gamma}} E_{t}\left(\left(\frac{1}{\kappa\left(1+\frac{\psi_{1}}{R_{T}^{B}}\right)}\right)^{1-\frac{1}{\gamma}}\left(\frac{\varphi_{T}}{\varphi_{t}}\right)^{1-\frac{1}{\gamma}}\right)-E_{t}\left(\frac{\varphi_{T}}{\varphi_{t}} \frac{1+\kappa \psi_{\circ}}{\kappa\left(1+\frac{\psi_{1}}{R_{T}^{B}}\right)}\right)= \\
=\varepsilon^{-\frac{1}{\gamma}} \varphi_{t}^{-\frac{1}{\gamma}} y_{1, t}-y_{2, t},
\end{gathered}
$$

where

$$
y_{1, t}=E_{t}\left(\left(\frac{1}{\kappa\left(1+\frac{\psi_{1}}{R_{T}^{B}}\right)}\right)^{1-\frac{1}{\gamma}}\left(\frac{\varphi_{T}}{\varphi_{t}}\right)^{1-\frac{1}{\gamma}}\right)
$$

and

$$
y_{2, t}=E_{t}\left(\frac{\varphi_{T}}{\varphi_{t}} \frac{1+\kappa \psi_{\circ}}{\kappa\left(1+\frac{\psi_{1}}{R_{T}^{B}}\right)}\right) .
$$

As $A_{0}=1$, the last expression could be reinterpreted as assets under management at time $t$ by means of the following equivalent expression.

$$
\begin{gathered}
A_{t}^{*}=\varepsilon^{-\frac{1}{\gamma}} \varphi_{t}^{-\frac{1}{\gamma}} y_{1, t}-y_{2, t}= \\
=\varepsilon^{-\frac{1}{\gamma}} \varphi_{t}^{-\frac{1}{\gamma}} E_{t}\left(\left(\frac{B_{T}}{\kappa} \frac{\varphi_{T}}{\varphi_{t}}\right)^{1-\frac{1}{\gamma}}\right)-\frac{q}{\kappa} E_{t}\left(B_{T} \frac{\varphi_{T}}{\varphi_{t}}\right)
\end{gathered}
$$

where

$$
B_{t} \equiv\left(1+\frac{\psi_{1}}{S_{t}^{B}}\right)^{-1}
$$

and

$$
q \equiv 1+\kappa \psi_{0} .
$$

\subsubsection{Optimal investment strategy}

Once, the optimal assets under management have been obtained, the claim that replicates the optimal strategy can be figured out:

$$
R_{t}^{A}=\varepsilon^{-\frac{1}{\gamma}} \varphi_{t}^{-\frac{1}{\gamma}} y_{1, t}-y_{2, t}
$$

the dynamics of the claim are given by:

$$
d R_{t}^{A}=\ldots d t-\frac{\partial R_{t}^{A}}{\partial \varphi_{t}} \varphi_{t} \Lambda^{\prime} d Z_{t}+\frac{\partial R_{t}^{A}}{\partial S_{t}^{B}} S_{t}^{B} \sigma_{B}^{\prime} d Z_{t}
$$

the drift term is omitted as it plays no role in this algebra. So, for any investment strategy $\theta_{t}$, it holds that 


$$
d R_{t}^{A}=\ldots d t+R_{t}^{A} \theta_{t}^{\prime} \Sigma d Z_{t}
$$

The optimal strategy is obtained by equating the diffusion terms in the last two equations:

$$
\begin{gathered}
\theta_{t}=\frac{1}{\gamma} \Sigma^{-1} \Lambda\left(\frac{R_{t}^{A}+y_{2, t}}{R_{t}^{A}}\right)+\frac{\partial R_{t}^{A}}{\partial S_{t}^{B}} \frac{S_{t}^{B}}{R_{t}^{A}} e_{1}= \\
=\frac{1}{\gamma} \Sigma^{-1} \Lambda\left(\frac{R_{t}^{A}+y_{2, t}}{R_{t}^{A}}\right)+\left(\varepsilon^{-\frac{1}{\gamma}} \varphi_{t}^{-\frac{1}{\gamma}} y_{1 t} \frac{\partial y_{1 t}}{\partial S_{t}^{B}} \frac{S_{t}^{B}}{y_{1 t}}-\frac{\partial y_{2 t}}{\partial S_{t}^{B}} \frac{S_{t}^{B}}{y_{2 t}}\right) \frac{1}{R_{t}^{A}} e_{1}= \\
=\frac{1}{\gamma} \Sigma^{-1} \Lambda \omega_{t}+\left(\omega_{t} \frac{\partial y_{11}}{\partial S_{t}^{B}} \frac{S_{t}^{B}}{y_{1 t}}+\left(1-\omega_{t}\right) \frac{\partial y_{2 t}}{\partial S_{t}^{B}} \frac{S_{t}^{B}}{y_{2 t}}\right) e_{1}= \\
=\frac{\omega_{t}}{\gamma} \Sigma^{-1} \Lambda+\left(\omega_{t} \xi_{t}^{y_{1}, S^{B}}+\left(1-\omega_{t}\right) \xi_{t}^{y_{2}, S^{B}}\right) e_{1}
\end{gathered}
$$

where

$$
\omega_{t}=\frac{R_{t}^{A}+y_{2, t}}{R_{t}^{A}}
$$

$\xi^{x, y}$ is the elasticity of $x$ with respect to $y$ at time $t$ and $e_{1}=(1,0)^{\prime}$.

This optimal portfolio can be decomposed into two parts. The first component, $\Sigma^{-1} \Lambda$, is the standard myopic demand that optimally exploits the risk-return trade off. ${ }^{11}$ The other component, $e_{1}$, is a benchmark replicating strategy. Both components are weighted by the dynamic variable, $\omega_{t}$ and the value of the CRRA of each manager, $\gamma$.

As $\gamma$ becomes larger, the manager's optimal portfolio converges to a pure benchmark replicating portfolio. The optimal portfolio fluctuates over time as a consequence of variations in $\omega_{t}$, which depends mainly on the fund's performance relative to the benchmark. So, as $A_{t}$ becomes larger, the optimal weight put on the benchmark becomes smaller.

\subsubsection{Structural interpretation of performance regressions}

It is common that performance regressions are used to assess the performance and risk exposure of a fund's manager. One important feature of the model above is that it can be rewritten in terms of the coefficients of a performance regression.

If the standard performance regression is formulated in continuous time:

$$
\frac{d A_{t}}{A_{t}}-r d t=\alpha_{t} d t+\beta_{t}\left(\frac{d S_{t}^{B}}{S_{t}^{B}}-r d t\right)+\sigma_{\xi t} d Z_{t}^{\xi}
$$

11 See Binsbergen et al. (2008). 
where the excess fund returns over the risk free asset, $\frac{d A_{t}}{A_{t}}-r d t$, are regressed against a constant $\alpha_{t} d t$ and excess benchmark returns, $\frac{d S_{t}^{B}}{S_{t}^{B}}-r d t$. The residual, $\sigma_{\xi_{t}} d Z_{t}^{\xi}$, is orthogonal to the benchmark returns and $Z_{t}^{\xi}$ is a standard Brownian motion. In this case, time-varying regression coefficients are allowed. In order to understand the link between (16) and the structural model, an equivalence starting from the manager's budget constraint will be derived:

$$
\begin{gathered}
\frac{d A_{t}}{A_{t}}-r d t=\theta_{t}^{\prime} \Sigma \Lambda d t+\theta_{t}^{\prime} \Sigma d Z_{t}= \\
=\theta_{A P t} \bar{\sigma}_{A P} \lambda_{A P} d t+\theta_{B t}\left(\frac{d S_{t}^{B}}{S_{t}^{B}}-r d t\right)+\theta_{A P t} \bar{\sigma}_{A P} d Z_{t}^{A P},
\end{gathered}
$$

where $\theta_{B t}$ and $\theta_{A P t}$ are the fractions invested in the benchmark and the active portfolio respectively. Given this last equation, the following equivalence between equations (15) and (16) can be shown:

$$
\begin{gathered}
\alpha_{t}=\alpha_{A P t} \bar{\sigma}_{A P} \lambda_{A P}, \\
\beta_{t}=\theta_{B t}, \\
\sigma_{\xi t}=\theta_{A P t} \bar{\sigma}_{A P}, \\
Z_{t}^{\xi}=Z_{t}^{A P}
\end{gathered}
$$

So, if the managers' budget constraint above is reformulated, it illustrates that it is possible to link the solution of the dynamic investment model to the coefficients of the performance regressions in this way.

If these expressions are worked out, they can give further intuition. If the optimal portfolio presented in (15) is substituted in the derived equivalences, it implies that:

$$
\begin{gathered}
\alpha_{t}=\omega_{t} \frac{\lambda_{A P}^{2}}{\gamma}, \\
\beta_{t}=\frac{\omega_{t}}{\gamma} \frac{\lambda_{B}}{\bar{\sigma}_{B}}+\left(1-\frac{\omega_{t}}{\gamma}\right),
\end{gathered}
$$

and

$$
\sigma_{\xi t}=\omega_{t} \frac{\lambda_{A P}}{\gamma}
$$

These three coefficients fluctuate over time due to $\omega_{t}$, this means that the performance regressions with constant coefficients may be misspecified. In the full model, a set of sufficient conditions for the three coefficients to become constant is that:

1. fund flows have no effect on assets under management, meaning $\psi_{\circ}=\psi_{1}=0$,

2. the base salary of the manager is tiny with respect to the variable component of the compensation, $\kappa \rightarrow \infty$. 
It is important to recall that the parameters $\psi_{0}, \psi_{1}, \lambda_{B}$, and $\bar{\sigma}_{B}$ are market-wide parameters, while the others parameters: $\lambda_{A P}, \kappa$, and $\gamma$ are specific to each manager. As well as $\alpha_{t}$, all of the manager specific parameters also enter in $\beta_{t}$ and $\sigma_{\xi t}$. As it was stated by Merton (1980), second moments can be estimated more accurately than first moments. The structural model provides economic constraints that link ability to both first and second moments of fund returns. This makes the maximum likelihood procedure an efficient procedure that blends the information in the first and second moments using the restrictions implied by the model. This combination results in a more precise estimates of ability than using only first moments.

Moreover, the managers' alphas are often taken as a measure of their skill. However, equation (18) shows that, although, alpha can be seen as a measure that reflects managerial ability, it also depends on the incentives and risk preferences of each manager. This result shows that it is nontrivial to properly measure managerial ability without a structural model, especially, if the manager follows a dynamic strategy ( $\omega_{t}$ fluctuates over time).

\subsection{Econometric Framework}

In order to compute the likelihood of this model and to estimate its parameters, the martingale method of Cox and Huang (1989) is used. This method has been extensively used to solve continuous-time optimization problems.

\subsubsection{The inference problem}

Among the data used in estimation, the benchmark returns are included, $r^{B T}, r_{t}^{B} \equiv$ $\ln S_{t}^{B}-\ln S_{t-h}^{B}$, and the mutual fund returns, $r^{A T}, r_{t}^{A} \equiv \ln A_{t}-\ln A_{t-h}$ of a given management company, where $z^{T} \equiv\left\{z_{h}, \ldots, z_{T}\right\}$. In this paper, $h$ is chosen to be 1 , this means that parameters will be obtained in monthly terms. The short rate, $r$, changes every month and is equal to the average of the daily 1-3 months T-bills rate.

The model parameters can be grouped into fund-flows parameters, $\Theta_{1} \equiv\left\{\psi_{0}, \psi_{1}\right\}$, that are common to all management companies that invest in the same benchmark, $\Theta_{2} \equiv$ $\left\{\lambda_{B}, \bar{\sigma}_{B}\right\}$ and the parameters that belong to each management company, $\Theta_{3} \equiv\left\{\lambda_{A P}, \kappa, \gamma\right\}$. Since the funds wealth dynamics no longer depend on $\bar{\sigma}_{A P}$, this parameter does not enter into the likelihood and cannot be identified from mutual fund returns.

Firstly, the parameters in $\Theta_{1}$ are estimated by means of the relationship between the relative returns and flows. Using annual data, the estimation is made through the following regression specification: ${ }^{12}$

$$
\frac{A_{t+2}-R_{t+2}^{A} A_{t+1}}{A_{t}}=\psi_{\circ}+\psi_{1} \frac{R_{t+1}^{A}}{R_{t+1}^{B}}+u_{t+2}
$$

\footnotetext{
12 In order to curb the impact of outliers, net inflows that supposes more than a 100 per cent of the assets under management of the previous year and net outflows higher than 70 per cent are not considered for this regression.
} 
where $A_{t+2}-R_{t+2}^{A} A_{t+1}$ is the gross flow from year $t+1$ to year $t+2$, this expression is divided by the assets at beginning of the investment period, $A_{t}$. These relative flows are explained by the variation in the relative returns that the management company is able to obtain between time $t$ and $t+1$. Parameters $\psi_{\circ}$ and $\psi_{1}$ are estimated using the full panel of flows and relative fund returns. The parameters estimates are denoted by $\widehat{\Theta}_{1}$.

The next step is to estimate the parameters contained in $\Theta_{2}$ and $\Theta_{3}$ conditional on $\widehat{\Theta}_{1}$. These sets of parameters will be estimated in a two step procedure, although, the joint log-likelihood of the benchmark and the fund returns should first be defined,

$$
\ln \mathcal{L}\left(r^{A T}, r^{B T} ; \widehat{\Theta}_{1}, \Theta_{2}, \Theta_{3}\right)=\sum_{t=h}^{\mathrm{T}} l\left(r_{t}^{\mathrm{A}}, r_{t}^{B} \mid r^{A, t-h}, r^{B, t-h} ; \widehat{\Theta}_{1}, \Theta_{2}, \Theta_{3}\right),
$$

and given this expression estimates for $\Theta_{2}$ and $\Theta_{3}$ should be found. One important feature of this log-likelihood is that it can be decomposed as:

$$
\begin{gathered}
\ln \mathcal{L}\left(r^{A T}, r^{B T} ; \widehat{\Theta}_{1}, \Theta_{2}, \Theta_{3}\right)=\sum_{t=h}^{\mathrm{T}} l\left(r_{t}^{B} ; \widehat{\Theta}_{1}, \Theta_{2}\right)+ \\
+\sum_{t=h}^{\mathrm{T}} l\left(r_{t}^{A} \mid r^{A, t-h}, r^{\mathrm{B}, \mathrm{t}} ; \widehat{\Theta}_{1}, \Theta_{2}, \Theta_{3}\right) .
\end{gathered}
$$

Given this decomposition, a two step procedure to estimate $\Theta_{2}$ and $\Theta_{3}$ can be applied. From the first term is trivial to estimate $\Theta_{2}$ because the out, estimates for $\Theta_{3}$ can be computed by means of the second term of theb benchmark return are normally distributed. Once, estimates $\Theta_{2}$ are figured last expression. The remainder of this section explains how to work out this second term of the log-likelihood.

\subsubsection{Construction of the likelihood using martingale methods}

The optimal terminal asset level, $A_{T}^{*}$ is supposed to be the outcome of the following optimization problem:

$$
\begin{aligned}
& \max _{A_{T} \geq 0} E_{\circ}\left[u\left(A_{T}, S_{T}^{B}\right)\right], \\
& \text { s.t. } E_{\circ}\left[\varphi_{T} \mathrm{~A}_{T}\right] \leq \mathrm{A}_{\circ},
\end{aligned}
$$

where (24) is the static representation of the dynamic budget constraint in (4). If the utility index is strictly concave, it holds that $A_{T}^{*}=I\left(\varepsilon \varphi_{T}, S_{T}^{B}\right)$, where $\varepsilon$ is the Lagrange multiplier that corresponds to the budget constraint and $I\left(., S_{T}^{B}\right)=\left(\frac{\partial u}{\partial A_{T}}\right)^{-1}\left(., S_{T}^{B}\right)$. By the no-arbitrage condition, time-t assets under management satisfy:

$$
\begin{gathered}
A_{t}^{*}=E_{t}\left[I\left(\varepsilon \varphi_{T}, S_{T}^{B}\right) \frac{\varphi_{T}}{\varphi_{t}}\right]= \\
\varepsilon^{\frac{1}{\gamma}} \varphi^{-\frac{1}{\gamma}} y_{1, t}-y_{2, t} .
\end{gathered}
$$

Since $y_{1, t}$ and $y_{2, t}$ depend only on $S_{T}^{B}$, there is a one to one mapping from assets under management to $\varphi_{t}$, conditional on $S_{T}^{B}$. This implies that observing assets under 
management, or fund returns, is equivalent to observing the time series of the state price density, $\varphi^{T}$.

If the Jacobian formula is applied, the following can be derived:

$$
\begin{aligned}
l\left(r_{t}^{A} \mid r_{t}^{B}, \varphi_{t-h} ; \widehat{\Theta}_{1}, \widehat{\Theta}_{2}, \Theta_{3}\right)=l\left(\Delta \ln \varphi_{t} \mid r_{t}^{B}, \varphi_{t-h} ; \widehat{\Theta}_{1}, \widehat{\Theta}_{2}, \Theta_{3}\right)+ \\
+\ln \left|\left(\frac{\partial\left(\Delta \ln A_{t}^{*}\right)}{\partial\left(\Delta \ln \varphi_{t}\right)}\right)^{-1}\right|
\end{aligned}
$$

where $\Delta z_{t}=z_{t}-z_{t-h}$. It should be noticed that $\varphi_{t-h}$ (likewise, $\left.A_{t-h}^{*}\right)$ contains all necessary relevant information at time $t-h$. As is further developed in the appendix, both terms in (25) can be computed by computing $y_{1, t}$ and $y_{2, t}$, for which two dimensional Guassian quadrature are used (Tauchen and Hussey (1991)). ${ }^{13}$

\subsubsection{Estimation procedure for $\widehat{\Theta}_{3}$}

When estimates of $\widehat{\Theta}_{1}$ and $\widehat{\Theta}_{2}$ are computed, the algorithm to estimate $\widehat{\Theta}_{3}$ starts from initial values and takes three main steps:

1. Computing the Lagrange parameters. In order to compute the Lagrange parameter for each year, $\varepsilon$, the budget constraint in (24) holds with equality. The expectation is approximated by means of quadrature methods. ${ }^{14}$ It is important to notice that this is a two dimensional integration, where $\ln S_{T} \sim N\left(\sum_{t=1}^{12} r_{t}+\right.$ $\left.+12 \bar{\sigma} \lambda_{B}-\frac{1}{2} \bar{\sigma}_{B} 12,12 \bar{\sigma}_{B}^{2}\right)$ and $\ln \varphi_{T} \sim N\left(-\sum_{t=1}^{12} r_{t}-\frac{1}{2} \lambda_{A P}^{2} 12-\lambda_{B} d Z_{T} \sqrt{12}, \lambda_{A P}^{2} 12\right)$. Given the optimal condition in (14), optimal $A_{T}^{*}$ can be computed. Each Lagrange multiplier, $\varepsilon$ is equal to:

$$
\varepsilon=\left(\frac{1+y_{2,0}}{y_{1,0}}\right)^{-\gamma}
$$

2. Recover the state-price density process. For each year and $t=1, \ldots, 12, \varphi_{t}$ is computed so that:

$$
A_{t}^{*}=E_{t}\left[\frac{\varphi_{T}}{\varphi_{t}} A_{T}^{*}\right]
$$

For finding each $\varphi_{t}, \varphi_{T}^{j}$ and $A_{T}^{* j}$ are computed until optimal $\varphi_{t}$ is figured out. Excellent starting values for $\varphi_{t}$ for launching the process can be obtained by

13 In numerical analysis, a quadrature rule ia an approximation of the definite integral of a function, usually stated as a weighted sum of function values at specified points within the domain of integration. A standard n-point Gaussian quadrature rule is a quadrature rule constructed to yield and exact result for polynomials of degree $2 \mathrm{n}-1$ or less by a suitable choice of the points $x_{i}$ and weights $w_{i}$ for $i=1, \ldots, n$. The domain of integration for such a rule is conventionally taken as $[-1,1]$, so the rule is stated as: $\int_{-1}^{1} f(x) d x=\sum_{i=1}^{n} w_{i} f\left(x_{i}\right)$. In this paper, 25 quadrature points were used. Increasing the number of quadrature points does not affect the result at the reported precision.

14 For these calculations, 25 quadrature points were used. Since using more points increases the computational burden, one can follow Fernandez-Villaverde et al. (2006) to select the number of points to use. Alternatively, Monte Carlo procedures could be used, but as it is stated in Koijen (2007), they are less accurate. 
using the passive fund innovation $d Z_{t}^{B}$ and the state-price density of the previous period $\varphi_{t-1}$.

3. Compute the log-likelihood contributions. Given each year time series of $\varphi_{t}$, the likelihood as in (25) can be constructed. This only requires one additional computation:

$$
\ln \left|\left(\frac{\partial \ln A_{t}^{*}}{\partial \Delta \ln \varphi_{t}}\right)^{-1}\right|
$$

where the derivatives are performed numerically.

The algorithm keeps performing until expression (25) reaches their maximum likelihood. The search algorithm used to obtain possible values for $\Theta_{3}$ is a Nelder-Mead type. $^{15}$

15 The Nelder-Mead algorithm or simplex search algorithm is one of the best known algorithms for multidimensional unconstrained optimization. For further details about this algorithm, see Nelder and Mead (1965). 



\section{Data}

The model is estimated for the Spanish equity mutual fund market whose investment feasible set is within the Eurozone. Most of the these mutual funds invest in the Spanish equity market or follow the Eurostoxx 50 as a benchmark. The main original source of the data set for this market is the Spanish Securities and Exchange Commission (CNMV). This institution periodically collects information as part of its duty to supervise collective investment schemes. Data on all existing equity mutual funds and the type (independent or not) of their management companies were obtained on a monthly basis from January 1995 to December 2014. The other source was Datastream, from which, monthly quotas for all considered benchmarks were obtained.

Although the CNMV collects data on all mutual funds registered in Spain, this paper and its methodology only consider equity mutual funds whose investments are within the Eurozone. The reasons why the analysis is restricted to these mutual funds are twofold: first, the equity funds that invest outside the Eurozone can contain negative and positive yields from forex. The other reason concerns proximity of management companies to their investment feasible set. It is more likely that managers actively choose investments different from a benchmark when they are close to the market they invest in, as it may the case for the Spanish and the Eurozone markets.

Treating each mutual fund/month as a single observation, the total sample size is 31,212 observations and the total number of funds considered is 228. It is important to point out that for a fund to be part of the database, it was required to be in the market for at least three fiscal years and its average total assets, over the period it is in the market, were to be over three million euros. The information obtained for each fund was:

1. Net Assets Value (NAV): funds' per share market value at the end of each month.

2. Total Assets: funds' total assets at the end of each month.

3. Annual Fees: defined as the sum of the management and depositary fees, $1 / 7$ of the subscription fee and $1 / 7$ of the redemption fee of each fund in each of the periods making up the sample. ${ }^{16}$

4. Benchmark: because current equity funds are obliged to declare their benchmark, this information has been used when available. ${ }^{17}$

16 This variable has been defined as in Gavazza (2011), Cambon and Losada (2014) and Losada (2015). It is assumed that investors invest over a time horizon of seven years.

17 In the case of some defunct funds, their benchmark has been determined by other procedure that will be further explained latter. 
Each mutual fund's management company has been assessed as belonging to a credit institutions or being independent. Among the 228 mutual funds, 77 belong to independent management companies whereas the other 151 are administrated by management companies which belong to credit institutions. In this paper, individual managers within each management company have not been assessed, instead, it is assumed that each fund is managed by the whole management company. Under this assumptions, the results on ability can be directly assigned to the management companies as they can be seen as an average of the talent they employ in-house.

From 2008, Spanish mutual funds began to have multiple share classes associated with different fee structures. Consistent with the literature, the different classes were merged into a single mutual fund. Value-weighted returns and fees were built up using the total net assets of the different classes of shares.

The CNMV database provides net assets value that are net of fees and other expenses. To better focus on managerial ability, gross returns are computed by adding back fees in line with Cohen et al. (2005). The annual fees divided by 12 are summed to each monthly return in a particular year.

In order to disentangle managerial skill and effort from the reward of the passive strategies, one important issue of the data gathering is how to decide which benchmark each mutual fund follows. As pointed out above, where possible, this information was gathered from the mutual fund prospectus, where it was not possible, a benchmark selection procedure was set up. ${ }^{18}$ This methodology is a regressionbased procedure. For these mutual funds, the returns are regressed on benchmark returns, both in excess of the short rate. Using the regression results, the benchmark that maximizes the R-squared is selected. To mitigate concerns that funds and benchmarks are matched incorrectly, the funds for which the maximum Rsquared value across all performance regressions does not exceed 80 per cent were omitted.

Twelve possible benchmark are considered as suitable for the analyzed equity mutual funds. These benchmarks are: Eurostoxx 50, IGBM, IBEX 35, IBEX Medium Caps, IBEX Small Caps, 50 per cent IBEX Small Caps-50 per cent IBEX Medium Caps, MSCI Spain, 50 per cent IBEX 35-50 per cent Eurostoxx 50, MSCI EMU Small Cap, Stoxx Mid 200, 50 per cent IBEX 3550 per cent IBEX Medium Caps, Stoxx 600. All indexes data were obtained from Datastream.

Finally, the data for the risk free-asset, in this case monthly returns of 1-3 months T-bills from the Spanish Treasury, were also obtained from Datastream.

18 Benchmark selection is notoriously difficult, regardless of whether one relies on regression techniques, matched characteristics, or self-reported benchmarks. On this token, Chan et al. (2009) and Sensoy (2009) provide different benchmark selection methodologies. Brown and Goetzmann (1995) provide an interesting alternative regression-based selection methodology. 
Table 1 provides summary statistics for the data used in the empirical analysis:

Descriptive statistics of the data set

\begin{tabular}{lcc} 
& Mean & Standard deviation \\
\hline Mutual Funds TNA (millions euros) & 53.4 & 108.2 \\
\hline Mutual Funds returns (Annual) & 2.76 & 20.82 \\
\hline Benchmark returns (Annual) & 5.52 & 19.08 \\
\hline Fee (Annual) & 1.99 & 0.81 \\
\hline Risk free asset return (Annual) & 3.07 & 2.26 \\
\hline Number of observations & \multicolumn{2}{c}{31212} \\
\hline Number of funds & 228 \\
\hline
\end{tabular}

Source: CNMV and Datastream. 



\section{Results}

\subsection{Estimates of the structural parameters}

The structural model for each fund is estimated separately. The main advantage of this approach is that any correlation between active returns across funds is allowed. The parameters that are assumed common to all funds are the parameters of the model for fund flows (see equation (21)). The estimated parameters were found equal to $\widehat{\psi}_{\circ}=-0.79$ and $\widehat{\psi}_{1}=-0.82$. These estimates mean that one per cent of outperformance of the fund relative to benchmark is translated into a 0.82 per cent of net inflows for the fund.

When estimating parameters for each mutual fund, for all individual funds and parameters, they were found to be significant. Table 2 summaries several statistics of the cross-sectional distribution of parameter estimates across all management companies. For each parameter, the cross-sectional mean, standard deviation, and the 25 (Q25), $50\left(Q_{50}\right)$, and $75\left(Q_{75}\right)$ percentiles are reported.

\section{Structural parameters estimates}

TABLE 2

\begin{tabular}{lccccc} 
& Mean & St dev & Q25 & Q50 & Q75 \\
\hline Ability $\left(\lambda_{A P}\right)$ & 0.05 & 0.04 & 0.03 & 0.04 & 0.05 \\
\hline Risk aversion $(\gamma)$ & 2.52 & 17.02 & 0.56 & 0.73 & 1.06 \\
\hline Incentive pay $(\kappa)$ & 62995.31 & 104655.04 & 0.91 & 1.45 & 2.12 \\
\hline \multicolumn{1}{c}{$\operatorname{Corr}\left(\lambda_{A P}, \gamma\right)=34.1 \%$} & & $\operatorname{Corr}\left(\lambda_{A P}, \kappa\right)=9.8 \%$ & \multicolumn{2}{c}{$\operatorname{Corr}(\gamma, \kappa)=-0.8 \%$} \\
\hline
\end{tabular}

Source: Own calculations.

The price of active risk, $\lambda_{A P}$, can be interpreted as the information ratio in continuous time. ${ }^{19}$ This parameter has a mean of 0.05 , it is right-skewed and the its median is 0.03 . The standard deviation across management companies is 0.04 which highlights that there is heterogeneity in managerial ability. These results contrast with the ones in Koijen (2014), where he found that for the U.S. market, the average was $\lambda_{A P}=0.12$ and the standard deviation was 0.13. Although the two databases do not cover the same sample period, this difference between the two markets deserves a further explanation.

The most evident factor is that the U.S. investors may enjoy more talent from their management companies. This may be the consequence of a low degree of competition in the Spanish mutual funds market as stated in Cambon and Losada (2014)

19 The information ratio is defined as the alpha relative to residual risk. 
and Losada (2015). The management companies may not compete in ability. As stated in Losada (2015), they may compete in less aggressive dimensions as a result of offering a wide variety of funds. ${ }^{2 \circ}$ The other reason may be found in the characteristics of the equity markets that the analyzed funds invest in, mainly the Spanish equity market and the European market for blue chips. These markets may be considered narrow, which may make it difficult to construct an alternative portfolio with equities that are not closely correlated with the benchmarks. It is difficult to disentangle which of these reasons is the main driver of the low ability shown by the data. Nevertheless, although it could be argued that there is a general problem of lack of competition in the Spanish mutual fund industry, this problem is much smaller in the equity mutual fund market.

The estimates of the CRRA coefficient, $\gamma$, average 2.52 and the median is 0.73 . In comparison with the results of Koijen (2014), the Spanish management companies are less risk averse. Results on both parameters show that the managers' alpha, which is usually interpreted as a measure of skill, has embedded within it both, skill and risk aversion. The coefficient of variation of both parameters, which is defined as the standard deviation divided by the mean, is 6.7 for $\gamma$ and 1.2 for $\lambda_{A P}$. This suggests that heterogeneity in alphas may mainly reflect the heterogeneity in risk preferences, especially for the management companies with a high risk aversion.

The parameter $\kappa$, which is the measure of the sensitivity of the management company's compensation contract to the mutual funds performance, has a very high average and standard deviation. This is because for about two per cent of funds, the estimated $\kappa$ is higher than 1000 . This implies, that for these funds, the base salary is only a negligible part of their total compensation. The quantiles of the cross-sectional show that estimated $\kappa$ is much smaller for most of the mutual funds. For the median fund, the variable compensation is about 60 per cent of the total compensation. This ratio only raises to about 66 per cent for the fund at the third quantile. In comparison with Koijen (2014), the dispersion of the variable component of the managers' compensation for most of the funds (up to the $75^{\text {th }}$ percentile) is much lower for the Spanish market. This shows that in Spain the compensation schemes are not so dependent on the managers' $\lambda_{A P}$ and $\gamma$ as they are in the U.S. market. This low dependence may also be reflected in the low correlation between $\kappa$ and $\lambda_{A P}$ and between $\kappa$ and $\gamma$ as shown in table 2 .

Benchmark parameters were estimated using the full time series of benchmark returns. The price of benchmark risk, $\lambda_{B}$ was found to be 0.21 , which can be interpreted as the benchmark's Sharpe ratio. The volatility of the benchmark results, $\sigma_{B}$, was estimated as 0.05 .

Table 2 also reports the correlation between $\lambda_{A P}$ and $\gamma$. This correlation is 34.1 per cent, which can be considered as a substantial correlation. Koijen (2014) provides two complementary explanations for this correlation. Part of the correlation may be the result of estimation error. In addition, this correlation may be the result of the behaviour of some skilled managers that are ahead of the benchmark and decide to

It is important to point out that in Cambon and Losada (2014), it was shown that the submarket of equity funds was even more competitive than the market of money market and fixed income mutual funds. 
reduce risk towards the end of the investment period. This last behaviour is known in the incentives literature as the "rachet effect".

Tables 3 and 4 show the parameters estimates for independent and nonindependent management companies. For the ability parameters, both types of management company enjoy levels of ability that can be considered very close. In this case, independent management companies do not show a higher ability. This type of management company enjoys a significant market share of $32.8 \%$ and as stated in Cambon and Losada (2012), they are especially present in the wholesale equity market. This evidence supports the hypothesis of the greater importance of the narrowness of the equity market the funds invest in, which gains prominence as the most likely explanation of why the ability estimates are lower than the ones in Koijen (2014).

\begin{tabular}{|c|c|c|c|c|c|}
\hline \multicolumn{5}{|c|}{$\begin{array}{l}\text { Structural parameters estimates: Non-independent management } \\
\text { companies }\end{array}$} & \multirow[b]{2}{*}{ Q75 } \\
\hline & Mean & St dev & Q25 & Q50 & \\
\hline Ability $\left(\lambda_{A P}\right)$ & 0.05 & 0.05 & 0.03 & 0.04 & 0.05 \\
\hline Risk aversion $(\gamma)$ & 1.59 & 4.79 & 0.60 & 0.78 & 1.20 \\
\hline Incentive pay $(\kappa)$ & 15511.31 & 200548.4 & 0.89 & 1.40 & 1.94 \\
\hline \multicolumn{2}{|c|}{$\operatorname{Corr}\left(\lambda_{A P, \gamma}\right)=8.9 \%$} & \multicolumn{2}{|c|}{$\operatorname{Corr}\left(\lambda_{A P}, \kappa\right)=0.5 \%$} & \multicolumn{2}{|c|}{$\operatorname{Corr}(\gamma, \kappa)=-2.0 \%$} \\
\hline
\end{tabular}

Source: Own calculations.

Structural parameters estimates: Independent management companies TABLE 4

\begin{tabular}{lccccc} 
& Mean & St dev & Q25 & Q50 & Q75 \\
\hline Ability $\left(\lambda_{A P}\right)$ & 0.05 & 0.04 & 0.03 & 0.04 & 0.06 \\
\hline Risk aversion $(\gamma)$ & 4.33 & 28.48 & 0.50 & 0.65 & 0.86 \\
\hline Incentive pay $(\kappa)$ & 3.04 & 6.26 & 1.03 & 1.55 & 2.41 \\
\hline \multicolumn{1}{c}{$\operatorname{Corr}\left(\lambda_{A P}, \gamma\right)=65.4 \%$} & & $\operatorname{Corr}\left(\lambda_{A P,}, \kappa\right)=-4.5 \%$ & $\operatorname{Corr}(\gamma, \kappa)=-6.4 \%$ \\
\hline
\end{tabular}

Source: Own calculations.

Although there is not much difference, as can be observed from the quartiles, most of the independent management companies are slightly less risk averse and their incentive schemes reward more the returns and new flows of the funds through the considered investment periods. The other feature that is worth highlighting is the difference in the correlation between $\lambda_{A P}$ and $\gamma$. The independent management companies shows a correlation of $65.4 \%$ whereas the others show a correlation of $8.9 \%$. This difference reflects the fact that incentives are different for the two types of management company.

The "raquet effect" is less important for non-independent management companies. Their investors are more loyal to them. It seems that they are less likely to quit their funds after a bad return in comparison with the investors of the independent management companies. 


\subsection{Structural model's alphas and betas}

As explained, once structural parameters are computed, one can figure out dynamic estimates for $\alpha_{t}$ and $\beta_{t}$ by using equations (18) to (20). In table 5 , the cross-sectional distribution of the parameters are reported from performance regressions and the structural model. In order to make feasible comparisons, for the case of the structural model, averages of the monthly $\alpha_{t}$ and $\beta_{t}$ were computed:

Estimates of $\alpha$ and $\beta$ from the structural model and performance

TABLE 5 regressions

\begin{tabular}{cccccc}
\multicolumn{7}{c}{ Structural model } \\
\hline$a$ & Mean & St dev & Q25 & Q50 & Q75 \\
\hline$\beta$ & $0.34 \%$ & $0.47 \%$ & $0.10 \%$ & $0.18 \%$ & $0.40 \%$ \\
\hline \multicolumn{7}{c}{ Mean } & 0.17 & 0.85 & 0.94 & 1.02 \\
\hline$a$ & 0.94 & St dev & Q25 & Q50 & Q75 \\
\hline$\beta$ & $2.43 \%$ & $3.14 \%$ & $0.81 \%$ & $2.66 \%$ & $3.86 \%$ \\
\hline
\end{tabular}

Source: Own calculations.

From the table, it can be observed that the estimates for $\alpha$ are lower for the structural estimation whereas the $\beta$ estimates are higher. The structural model estimates assign a higher dependence between funds and their benchmarks. This could pick up some non-linear relationships that a linear model could not as they include in the estimation second order moments. This could explain, at least partly, why the structural model estimates lower alphas for funds. So, if the estimates from the structural model were correct, this would imply two consequences. First, the mutual fund performance from the active portfolio is very small. ${ }^{21}$ Second, one of the reasons for this poor performance is that the active portfolio is smaller than one would think from the results of the performance regressions.

\subsection{On active management}

As discussed in the introduction, there has started a debate on whether mutual funds managers undertake active management or mainly follow a benchmark. Recently, the Swedish government expressed a concern on this issue. It was the first to investigate the existence of tracking funds that charge high fees for pretending active management when they do little more than mimic an index. On the same token, Denmark also launched an investigation and found that about a third of the domestic equity funds could be classified as closet trackers.

The academic literature has done little to investigate the incentives for active management. Most of papers related to this issue investigated whether active managed

21 These results are in line with previous literature on the performance of Spanish equity funds. See Ferrando and Lassala (1998), Basarrate and Rubio (1999), Matallin and Fernandez (1999), Menendez and Alvarez (2000), Martinez (2001), Fernandez et al. (2007) and Palacios (2010). 
funds perform betters than passive. For example, Dyck et al. (2013) found that active management outperformed passive management in emerging markets by more than 180 basis points in the period 1993 to $2008 .{ }^{22}$ In contrast, in the U.S. market, active management underperformed. However, these papers do not study the drivers of active management.

One of few papers that does study these incentives is Cremers and Petajisto (2009). This paper can be considered the most relevant to the discussion, it analyzes how active equity fund managers are in the U.S. market from 1980 to 2003. Although, traditionally active management has been measured by means of tracking errors, these authors add to the analysis a comparison between the portfolio holdings of mutual funds and their benchmarks. So, they introduced a novel ex-ante measure of active management where they disentangle the mutual fund portfolio in two separated portfolios, one as a benchmark replicated portfolio, the other is assimilated to the active portfolio. Among their main results, they found weak evidence that small funds are more active and they did not find a significant relationship between how active a mutual fund is and the fee charged to investors.

Through the structural model, this paper can also assess how active the management companies of Spanish equity mutual funds are. From equation (20), one can compute the expected volatility of the active portfolio of each mutual fund. Once, the latter is known, it is easy to compute the percentage of volatility for the active portfolio over the whole mutual fund portfolio. On average, the mean of the volatility of the active portfolio accounts for 28.7 per cent of the total mutual fund volatility, with a standard deviation of 14.8 per cent.

Tables 6 and 7 indicate the relationships between the size of the active portfolio and the the mutual fund fees and between the size of the active portfolio and the total mutual funds' assets. From table 6, it follows that there is not statistical relationship between the size of the active portfolio and the fees paid by the investors.

\section{Estimation results: size of the active portfolio us fund's fees}

\begin{tabular}{lccc} 
& \multicolumn{2}{c}{ Regression estimation } & \\
\hline Cons & Coeff & Stand.dev & p-value \\
\hline Fees & 0.25 & 0.026 & 0.00 \\
\hline F-test (p-value) & 1.87 & 1.24 & 0.13 \\
\hline R-square & & 0.13 & \\
\hline Number of observations & & 0.01 & \\
\hline
\end{tabular}

Source: Own calculations.

On the other hand, table 7 presents the results of the linear regression where the size of the active portfolio is the dependent variable and the fund's assets the independent variable.

22 Other related papers are Wermers (2000), Wermers (2003) or Kacpercyzk et al. (2005). 


\begin{tabular}{lccc} 
& \multicolumn{2}{c}{ Regression estimation } & \\
\hline Cons & Coeff & Stand.dev & p-value \\
\hline Fund's total assets & 0.31 & 0.01 & 0.00 \\
\hline F-test (p-value) & $-3.43 e^{-7}$ & $1.44 e^{-7}$ & 0.02 \\
\hline R-square & & 0.018 & \\
\hline Number of observations & & 0.025 & \\
\hline
\end{tabular}

Source: Own calculations.

In light of the regression results, it can be stated that there is a weak dependence between the size of the active portfolio and the fund's total assets. Only when the total fund's assests are above 100 million euros does, the size of fund matters and the active portfolio is expected to be small. The results on these two relationships are in line with Cremers and Petajisto (2009).

In addition to working out these two relationships, from the results of the structural model, two further interesting relationships can be studied. These are the relationship between the size of the active portfolio and the ability of the fund's management company and the relationship between the size of the active portfolio and the type of fund's management company (independent or not). In order to assess these two relationships, two regressions were run. The results are in tables 8 and 9 .

From the table 8, it can be shown that the more competent the management company, the bigger the active portfolio. This result flows naturally, as the managers seem to use their ability by running bigger active portfolios.

Estimation results:size of the active portfolio us ability

\begin{tabular}{lccc} 
& \multicolumn{2}{c}{ Regression estimation } & \\
\hline Cons & Coeff & Stand.dev & p-value \\
\hline ability & 0.21 & 0.01 & 0.00 \\
\hline F-test ( $p$-value) & 1.40 & 0.20 & 0.00 \\
\hline R-square & & 0.00 & \\
\hline Number of observations & & 0.17 & \\
\hline
\end{tabular}

Source: Own calculations.

From table 9, it can be observed the results of a regression where the type of management company is a dummy variable that takes a value 1 when the management company belongs to a credit institutions and o when it is independent. In this case, the regression results highlight how, on average, the management companies that belong to credit institutions run smaller active portfolios. So, as this type of management company enjoys the highest market shares, they may not need to take risks and prefer to track closer to the equity indexes. This may be a sign that this type of management company enjoys market power. In this segment of the market, anyhow, as stated in Cambon and Losada (2012), this market power should be lower than in other segments of the mutual fund market. 


\begin{tabular}{lccc}
\multicolumn{4}{c}{ Regression estimation } \\
& Coeff & Stand.dev & p-value \\
\hline Cons & 0.34 & 0.01 & 0.00 \\
\hline Type of management company & -0.07 & 0.02 & 0.00 \\
\hline F-test (p-value) & & 0.00 & \\
\hline R-square & & 0.06 & \\
\hline Number of observations & & 227 & \\
\hline
\end{tabular}

Source: Own calculations.

As a corollary, it could be argued that one might expect that independent management companies to choose bigger active portfolios for their smaller funds which are run by their more competent managers.

\subsection{Correlation between active fund returns}

As an outcome of the econometric procedure, the return of the active portfolio, $Z_{t}^{A}$ can be recovered. This is impossible without having estimated a structural model as the management company changes the portfolio over time. The section devoted to the econometric framework of this paper provides the means to recover, each month, the state-price density $\varphi_{t}$. As benchmark returns and log changes in the state-price density are homoscedastic, the monthly innovations, $Z_{t}^{A}$ can be recovered for each management companies. ${ }^{23}$

The pairwise correlation is first computed. The estimation procedure does not impose ex-ante any constraint on the correlation structure, but the average correlation between active returns between any two funds can be computed in a given year. If these correlations are averaged over time, it comes to about 20 per cent. This correlation can be considered as low although it is higher than the one reported in Koijen (2014) where he reported a figure of 5 percent. One possible explanation for this difference may be again that the Spanish equity market is narrower than the U.S. market. Anyhow, given the characteristics of the Spanish equity market, the correlation found for the Spanish market may be a sign of what was shown in Cremers and Petajisto (2009), who found evidence of active bets in the mutual fund industry that tend, as far as possible, to cancel out.

To show the average time-series dynamics of changes $Z_{t}^{A}$, the monthly average of changes across funds was computed. Figure 1 displays the 12 month moving-average of the time series from January 1995 to December 2014. This period covers two crisis in the Spanish equity markets, the first at the beginning of the 2000 s was the bursting of the dot-com bubble. The second starts in 2008 and covers what is coming to be known as the Great Recession.

23 The average monthly increment in $Z_{t}^{A}$ across al managers is near zero $(-0.001)$, and the standard deviation is 0.4852 , which is a bit higher than its theoretical value of $\sqrt{ } 12=0.2887$. This difference can be a consequence of the equity markets high volatility since the beginning of the financial crisis. 


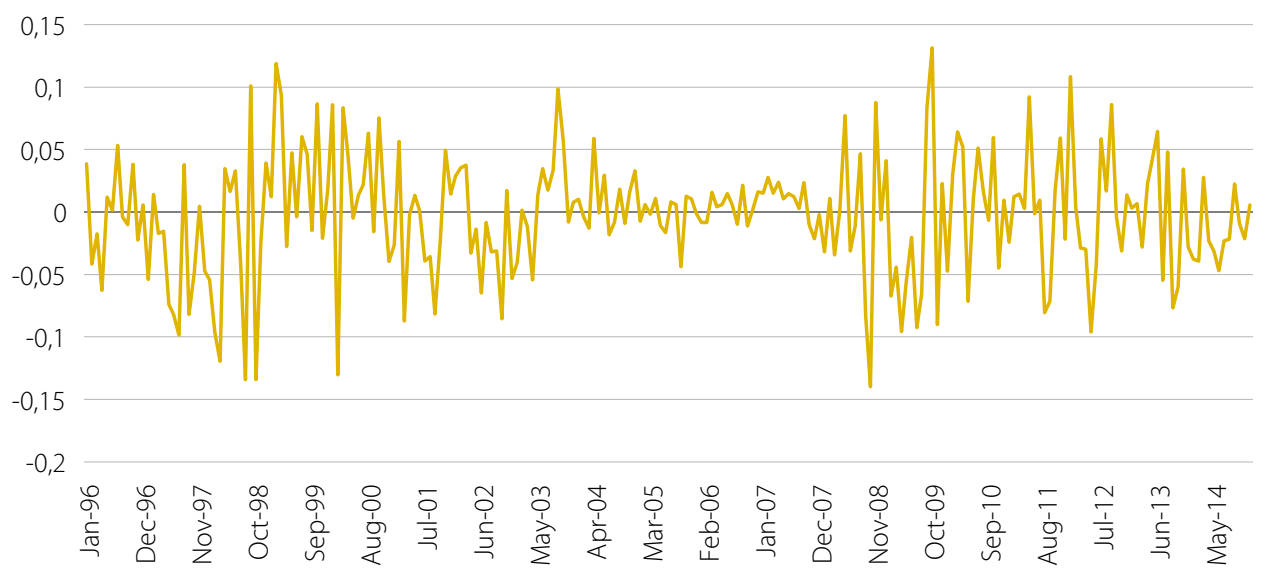

Source: Own source.

Contrary to Kosowski (2006), Kacperczyk et al. (2010) and Koijen (2014), who found evidence that mutual funds tend to outperform their benchmarks in recessions, the same result cannot be derived from this empirical analysis. This result may be a consequence of one or both of the following reasons. The first is that management companies do not feel the pressure of outperforming the benchmarks in recessions. Although it is very likely that there will be net outflow in these periods, they incur a moral hazard problem as they may think they cannot avoid them by increasing their efforts. The second reason is that, in recessions, they do not have enough available equity investments that are different from the benchmark to allow them to outperform. 


\section{Conclusions}

A dynamic structural model of equity mutual fund performance, based on Koijen (2014), has been estimated. The primitives of the model are the manager's risk aversion, compensation contract, and ability. Through econometric techniques, the model's likelihood was constructed, which in turn allows maximum-likelihood estimation of the structural parameters. The model was estimated for Spanish equity funds investing in assets on the domestic market or the Eurozone in the period 1995 to 2014 .

As stated by Koijen (2014) for the U.S. market, the result of the model estimation suggests that a fund's alpha does not depend only on the ability of the manager, it also depends on his preferences and his compensation contract. Heterogeneity in the parameters were found. This result indicates that alphas are not a perfect mirror of managers' ability in the Spanish equity mutual funds market.

When the average managers' ability is compared with the result in the U.S. market, it can be seen that ability in the latter is higher, 0.12 versus 0.05 . This difference may be the consequence of two effects, separately or in combination. The first effect comes from the lack of competition in the Spanish mutual fund market, as documented in Cambon and Losada (2014) and Losada (2015). Nevertheless, there is evidence that the competition is stronger in the equity mutual funds niche, where there are more competing independent management companies. The other reason should be found in the narrowness of the Spanish equity market and the European blue chip market. Managers may find it difficult to construct alternative portfolios that allow them to get extra performance for their funds compared to following a benchmark.

Within the Spanish market, the difference in ability between managers from independent and nonindependent management companies was assessed. It was found that there is not a significant differences between these two types of management company. However, there is evidence that their managers do follow a different incentive scheme when deciding their portfolios. As independent management companies' investors are less loyal, they try to smooth their mutual funds returns over the years in comparison with benchmarks. When managers use this strategy, their investors seem to quit their funds with a lower probability. The managers of the non-independent sector do not need to smooth their mutual funds returns as their investor are more loyal and can tolerate more volatile returns.

When the results from the structural model are compared with the ones from the CAPM performance regressions, the alphas from the structural model are lower on average whereas the betas are higher. The structural model assigns a higher dependence between the funds and their benchmarks. This could pick up some non-linear 
relationships that a linear model could not. If the estimates from the structural model are taken as correct, this imply two consequences. First, the equity funds average performance from the active portfolio is poor. Second, one of the main reason for the poor performance is that the active portfolio is smaller than one would think from the performance regressions results.

Recently, a debate has started on whether managers of equity funds are active when choosing their portfolio. Some Scandinavian countries have concerns over whether managers mainly follow a benchmark or perform actual active management. Following these concerns, this paper also evaluated how active managers are in the Spanish market. Through the results of the structural model, the contribution of the active part to the whole portfolio can be measured. This contribution is, on average, the 28.7 per cent of the total fund's volatility, with a standard deviation of 14.8 per cent.

In addition to these measures, this analysis studied the relationship between the size of the active portfolio and different features of the mutual funds and management companies comprising: funds' fees, size of mutual funds (total assets), ability of the management companies and the type of management companies. First, not relationship between the size of the active portfolio and the fees paid by the investors was found. With regard to the second feature, there was a weak negative relationship between the size of the active portfolio and the total assets of the mutual funds. Only when the total fund's assets are above 100 millions euros, the active portfolio is expected to be notably small. These two result are in line with previous literature. With respect to the other two relationships, it was found that the higher the ability of a management company, the bigger the size of the active portfolio. It was also found that the active portfolio is bigger the independent management companies.

The outcomes of the structural model were also used to assess how mutual funds' active portfolio performed in recessions. Some previous literature showed that equity funds tend to behave better in recessions by outperforming their benchmarks. According to this analysis, this does not happen for the Spanish market. This result may be the consequence of one of both of the following reasons. Although, it is very likely that there would be net outflow in recessions, they incur a moral hazard problem as management companies may think that they cannot avoid them by increasing their efforts. The other reasons is that, they do not have enough available equity investments that are different from the benchmark in order for them to outperform it. 


\section{References}

[1] Ackermann, C., McNally, R. and Ravenscraft, R. (1999). "The performance of hedge funds: risk, return and incentives". Journal of Finance, vol LIV, pp 833874 .

[2] Basak, S., Pavlova, A. and Shapiro, A. (2007). "Optimal asset allocation and risk shifting in money management". Review of Financial Studies, vol 20, pp 15831621.

[3] Basarrate, B. and Rubio, G. (1999). "Nonsimultaneous prices and the evaluation of management portfolios in Spain”. Applied Financial Economics, vol 9, pp $273-281$.

[4] Binsbergen, J.H., Brandt, M. and Koijen, S. (2008). "Optimal decentralized investment management”. Journal of Finance, vol LXIII, pp 1849-1895.

[5] Brown, S. and Goetzmann, W. (1995). "Peformance persistence". Journal of Finance, vol L, pp 679-698.

[6] Cambon, M.I. and Losada, R. (2012). "Development of mutual fund managers and products offered from 1995 to 2010”. CNMV Quartely Bulletin, Q1, pp 87-108.

[7] Cambon, M.I. and Losada R. (2014). "Competition and structure of the mutual fund industry in Spain: the role of credit institutions". Spanish Review of Financial Economics, vol 12, pp 58-71.

[8] Chan, L., Dimmock, S. and Lakonishok, J. (2009). "Benchmarking money manager performance: issues and evidence”. Review of Financial Studies, vol 22, pp 4453-4499.

[9] Cohen, R., Coval, J. and Pastor, L. (2005). "Judging fund managers by the company they keep”. Journal of Finance, vol LX, pp 1057-1096.

[10] Chapman, D., Evans, R. and Xu, Z. (2010). "The portfolio choices of young and old active mutual fund managers". Working paper, Boston College.

[11] Cohen, R., Coval J. and Pastor, L. (2005). "Judging fund managers by the company they keep". Journal of Finance, vol LX, pp 1057-1096.

[12] Cox, J. and Huang, C. (1989). "Optimal consumption and portfolio policies when asset prices follow a diffussion process". Journal of Economic Theory, vol 49, pp 33-83. 
[13] Cremers, M. and Petajisto A. (2009). "How active is your fund manager? A new measure that predicts performance". Review of Financial Studies, vol 22, pp 3329-3365.

[14] Detzler, M.L. (1999). "The performance of global bond mutual funds". Journal of Banking and Finance, vol 23, pp 1195-1217.

[15] Droms, W.G. and Walker, D.A. (1995). "Determinants of variation in mutual fund returns". Applied Financial Economics, vol 5, pp 383-389.

[16] Dyck, A., Lins, K. and Pomorski, L. (2013). "Does active management pay? New international evidence”. Review of Assets Pricing Studies, vol 3, pp 200-228.

[17] Edelen, R.M. (1999). "Investor flow and assessed performance of openend mutual funds". Journal of Financial Economics, vol 53, pp 439-466.

[18] Fernandez, P., Carabias, J.M. and Miguel, L. (2007). "Rentabilidad de los fondos de inversion de renta variable nacional en España 1991-2006”. IESE working paper.

[19] Fernandez-Villaverde, J., Rubio J. and Santos, M. (2006). "Convergence properties of the likelihood of computed dynamic models". Econometrica, vol 74, pp 93-119.

[20] Ferrando, M. and Lassala, C. (1998). "Evaluacion de la gestion de los FIAMM y de los FIM de renta fija en España en el periodo 1993-1995”. Revista Española de Financiacion y Contabilidad, vol 94, pp 197-231.

[21] Gavazza, A. (2011). "Demand spillovers and market outcomes in the mutual fund industry”. RAND Journal of Economics, vol 42, pp 776-804.

[22] Grinblatt, M. and Titman, S. (1989). "Mutual fund performance: an analysis of quartely portfolio holdings", Journal of Business, vol 62, pp 393-416.

[23] Jensen, M. (1968). "The performance of mutual funds in the period 1945-1964". Journal of Finance, vol XXIII, pp 389-416.

[24] Kacperczyk, M., Sialm, C. and Zheng, L. (2005). "On industry concentration of actively managed equity mutual funds". Journal of Finance, vol LX, pp 19832011.

[25] Kacperczyk, M., Van Nieuwerburgh, S. and Veldkamp, L. (2010). "Attention allocation over the business cycle". NYU Stern working paper.

[26] Koijen, R. (2014). "The cross-section of managerial ability, incentives, and risk preferences". Journal of Finance, vol LXIX, pp 1051-1098.

[27] Koijen, R. (2007). "Likelihood-based estimation of dynamic models of delegated portfolio management". Working paper NYU Stern School of Business. 
[28] Kosowski, R. (2006). "Do mutual funds perform when it matters most to investors? Mutual fund performance and risk in recessions and expansions". Tanaka Business Scholl working paper, Imperial College of London.

[29] Losada, R. (2015). "Measuring marke power in the Spanish mutual fund industry for retail investors”. Mimeo.

[30] Lynch, A. W. and Wachter, J.A. (2007a). "Does mutual fund performance vary over the busines cycle?" Working paper NYU Stern and The Warthon School.

[31] Lynch, A. W. and Wachter, J.A. (2007b). "Using samples of unequal length in generalized method of moments estimation". Working paper NYU Stern and The Warthon School.

[32] Malkiel, B. (1995). "Returns from investing in equity mutual funds 19711991". Journal of Finance, vol L, pp 549-572.

[33] Martinez, M.A. (2001). "El puzzle de los fondos de inversion en España: un enfoque de demanda”. Moneda y Credito, vol 213, pp 129-154.

[34] Matallin, J.C. and Fernandez, M.A. (1999). "Analisis de la performance a traves del estilo del fondo de inversion”. Revista Española de Financiacion y Contabilidad, vol 28, pp 413-442.

[35] Menendez, S. and Alvarez, S. (2000). "La rentabilidad y la persistencia de los resultados de los fondos de inversion de renta variable". Revista Española de Financiacion y Contabilidad, vol 103, pp 15-36.

[36] Merton, R. (1980). "On estimating the expected return on the market". Journal of Financial Economics, vol 8, pp 323-361.

[37] Nelder, J. A. and Mead, R. (1965). "A simplex method for function minimization". Comput. J., vol 7, pp 308-313.

[38] Nielsen, L. T. and Vassalou, M. (2004). "Sharpe ratios and alphas in continuos time". Journal of Financial and Quantitative Analysis, vol 39, pp 103-114.

[39] Palacios, J. (2010). "A vueltas con los fondos de inversion españoles: nuevas sorpresas en la decada 2000-2009”. IESE working paper.

[40] Pastor, L. and Stambaugh F. (2002). "Mutual fund performance and seemingly unrelated assets." Journal of Financial Economics, vol 63, pp 315-349.

[41] Sensoy, B.A. (2009). "Performance evaluation and self-designated benchmark indices in the mutual fund industry". Journal of Financial Economics, vol 92, pp 25-39.

[42] Sharpe, W. (1966). "Mutual fund performance". Journal of Business, vol 39, pp 119-138. 
[43] Tauchen, G. and Hussey, R. (1991). "Quadrature-based methods for obtaining approximate solutions to nonlinear asset pricing models". Econometrica, vol 59, pp 371-396.

[44] Wermers, R. (2000). "Mutual fund performance: an empirical decomposition into stock-picking talent, style, transactions costs, and expenses". Journal of Finance, vol LX, pp 1655-1695.

[45] Wermers, R. (2003). "Are mutual fund shareholders compensated for active management bets?" University of Maryland working paper.

[46] Wermers, R. (2011). "Performance measurement of mutual funds, hedge funds, and institutional accounts". Annual Review of Financial Economics, vol 3, pp 537-574. 


\section{Appendix A. Econometric approach}

In this appendix, further details on the econometric approach are provided. ${ }^{24}$ The likelihood of the model is calculataed as in (23). In order to compute the likelihood, the time series of the state-price density given the time series of assets under management and benchmark returns are recovered. Given the equation of assets under management, it can be derived that the state-price density is equal to:

$$
\varphi_{t}=\left(\frac{A_{t}+y_{2, t}}{y_{1, t}}\right)^{-\gamma} \varepsilon^{-1}
$$

where $y_{1, t}$ and $y_{2, t}$ depend on $S_{t}^{B}$ :

$$
\begin{gathered}
y_{1, t}=E_{t}\left(\left(\frac{1}{\kappa\left(1+\frac{\psi_{1}}{R_{T}^{B}}\right)}\right)^{1-\frac{1}{\gamma}}\left(\frac{\varphi_{T}}{\varphi_{t}}\right)^{1-\frac{1}{\gamma}}\right) \\
\mathrm{y}_{2, t}=E_{t}\left(\frac{\varphi_{T}}{\varphi_{t}} \frac{1+\kappa \psi_{\circ}}{\kappa\left(1+\frac{\psi_{1}}{R_{T}^{B}}\right)}\right)
\end{gathered}
$$

and $R_{T}^{B}=\frac{S_{T}^{B}}{S_{0}^{B}}$. Both expectations are computed by means of Gaussian quadratures. When the time series of the state-price density is worked out, it is straightforward to compute the first term in (24), as it follows a geometric Brownian motion. The last step consists in computing the correction term in the log-likelihood:

$$
\ln \left|\left(\frac{\partial\left(\ln A_{t}-\ln A_{t-\mathrm{h}}\right)}{\partial \Delta \ln \varphi_{t}}\right)^{-1}\right|=\ln \left|\left(\frac{\partial \ln A_{t}}{\partial \Delta \ln \varphi_{t}}\right)^{-1}\right|
$$

As:

$$
\begin{gathered}
A_{t}=\varepsilon^{-\frac{1}{\gamma}} \varphi_{t}^{-\frac{1}{\gamma}} y_{1, t}-y_{2, t}= \\
=\varepsilon^{-\frac{1}{\gamma}} \varphi_{t-\mathrm{h}}^{-\frac{1}{\gamma}}\left(\frac{\varphi_{t}}{\varphi_{t-\mathrm{h}}}\right)^{-\frac{1}{\gamma}} y_{1, t}-y_{2, t}= \\
=\varepsilon^{-\frac{1}{\gamma}} \varphi_{t-\mathrm{h}}^{-\frac{1}{\gamma}} \exp \left(-\frac{1}{\gamma} \Delta \ln \varphi_{\mathrm{t}}\right) y_{1, t}-y_{2, t} .
\end{gathered}
$$

24 For further details and extension of this model, see Koijen (2014). 
This implies for the partial derivative in the correction term that:

$$
\begin{gathered}
\frac{\partial \ln A_{t}}{\partial \Delta \ln \varphi_{t}}=\frac{1}{A_{t}} \frac{\partial A_{t}}{\partial \Delta \ln \varphi_{t}}= \\
=\frac{1}{A_{t}}\left(-\frac{1}{\gamma} \varepsilon^{-\frac{1}{\gamma}} \varphi_{t-\mathrm{h}}^{-\frac{1}{\gamma}} \exp \left(-\frac{1}{\gamma} \Delta \ln \varphi_{t}\right) y_{1, t}\right)= \\
=\frac{1}{A_{t}}\left(-\frac{1}{\gamma} \varepsilon^{-\frac{1}{\gamma}} \varphi_{\mathrm{t}}^{-\frac{1}{\gamma}} y_{1, t}\right)= \\
=-\frac{1}{\gamma} \frac{A_{t}+y_{2, t}}{A_{t}}
\end{gathered}
$$

This implies that the correction term is:

$$
\ln \left|\left(\frac{\partial \ln A_{t}}{\partial \Delta \ln \varphi_{t}}\right)^{-1}\right|=\ln \gamma-\ln \left(1+\frac{y_{2, t}}{A_{t}}\right) .
$$



